\title{
Systematic integration of PV plants and energy storage systems into low voltage grid
}

\author{
Ralph Samulowitz* \\ Frankfurt University of Applied Sciences, Nibelungenplatz 1, Frankfurt am Main 60318, Germany
}

\begin{abstract}
This paper shows a practical comparison of the project planning of a grid connected photovoltaic system with bifacial solar modules with an east west orientation and a saltwater storage systems. First is the Data collection to evaluate the performance of a PV system the knowledge of the load profile. Second is the Solar irradiation and plant design. The Frankfurt University of Applied Science connects high-resolution 3D photos with the cadastral land of the property registers The lay-out on self-consumption and autarky is compared to verify an optimum for a single-family household. The saltwater battery seems to be a promising alternative to lithium-ion batteries. A different study shall be consulted for the planning as a comparison and then be carried out in a practical plant.
\end{abstract}

Keywords: Cellular approach, solar bifacial module, electrical energy storage, saltwater battery

\section{Introduction}

With regard to the energy turn in Germany the expansion of alternative energy sources determines the renewable energies act (EEG). In particular the EEG provides the framework for power ranges of photovoltaic plants integrated into the electricity market. Plants sizes up to $10 \mathrm{kWp}$ are substantially relevant for residential home owners in the EEG. In the range between $10 \mathrm{kWp}$ and $1000 \mathrm{kWp}$ the EEG separately states PV solar parks.

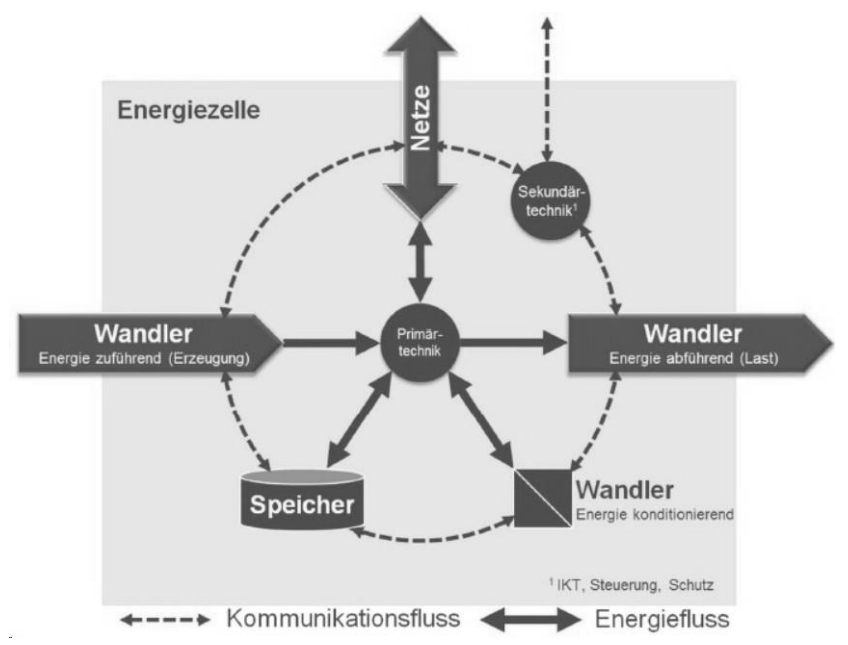

Fig. 1. VDE cellular approach.

*Manuscript received December 5, 2017; revised June 5, 2017.

Corresponding author. Tel.:+ 069797 3370; E-mail address: Ralph.Samulowitz@ siemens.com.

doi: $10.12720 /$ sgce.6.2.149-156 
Until 2009 the feed-in tariff for photovoltaic roof systems takes the complete generated power into consideration. Typically modules are installed with a south orientation in order to maximize the harvesting factor. During that time no self-consumption was common.

A first reduction of the feed-in tariff was introduced from 01-01-2009 to 31-03-2012 in the EEG. For this reason new plants are interpreted for the first time with a consumption of auxiliaries which corresponds to an average self-consumption rate of approximately $30 \%$.

The cellular approach introduced in the VDE Study [1] describes the basis of a successful interregional energy transition, Fig. 1. The target is to show the energy balance cell besides the energy flow. The communication is a second important role to complete the networking of the individual components.

The HTW Berlin Fig. 2 [2] shows the different current references at their model in a household [3] with a grid connection, a consumer, a photovoltaic plant and a storage battery.

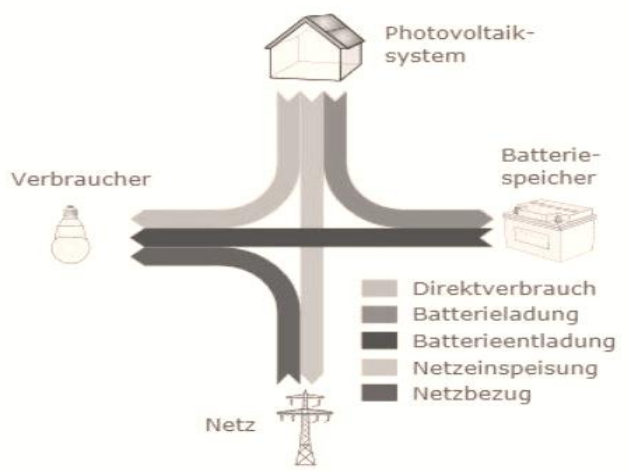

Fig. 2. HTW model [2].

\subsection{Self-consumption}

The self-consumption rate EVG (1) is defined by the ratio of the PV energy which is used directly $\mathrm{E}_{\mathrm{DU}}$ and the overall produced $\mathrm{PV}$ energy $\mathrm{E}_{\mathrm{PV}}$ :

$$
E V G=\frac{E_{D U}}{E_{P V}}
$$

An average value for most plants is approximately 35\%. If consumers like washing machines operate during the day the self-consumption can reach average values of about $45 \%$. Surplus power is fed into the public grid. In case of a plant with an additional battery the self-consumption rate can be increased up to values of approximately $65 \%$. In principal a self-consumption rate of $100 \%$ can be realized by the use of an oversized energy storage battery, however the cost-effectiveness as well as the autarky rate would drop dramatically.

\subsection{Autarky}

Re The autarky rate (2) is defined by the ratio of the directly used PV energy $E_{\mathrm{DU}}$ and the total load demand $\mathrm{E}_{\mathrm{L}}$ :

$$
A Q=\frac{E_{D U}}{E_{L}}
$$

An autarky quota of $100 \%$ can be realized in an off grid application with a PV plant and battery, e.g. remote alpine hut. Systems without storage batteries can reach an autarky rate of approximately $25 \%$, plants with small storage systems up to 50\%. On the other hand systems with an increasing battery capacity and a reduced PV plant can reach high autarky rates, however this leads an uneconomical 
solution with a low self-consumption rate.

\section{Data Collection of the Plant}

To evaluate the performance of a PV system the knowledge of the load profile of a private household for the different periods of year (winter, summer, transition time period) is required. With this information an energy balance and the dimensioning of the plant can be carried out. For this purpose an electricity meter is used at the point of connection to the public grid. Data are stored with a sampling interval of 15 minutes [3].

\subsection{Winter period}

Fig. 3 depicts the energy consumption with a resolution of 15 minutes (red columns) for a one singlefamily house during a winter day. The blue line indicates the accumulated energy consumption.

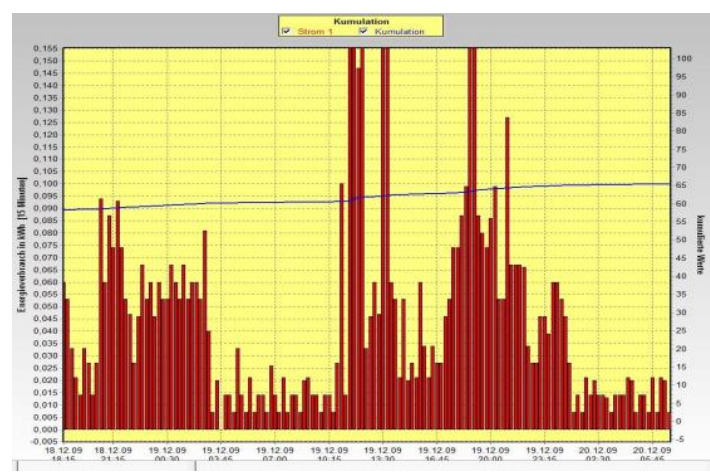

(a)

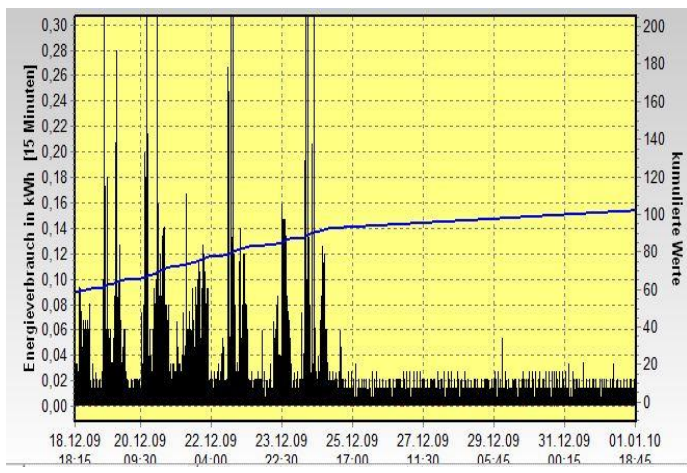

(b)

Fig. 3. Measured in winter: (a) daily load curve (b) Week measuring.

Fig. 3a shows the typical peaks during the morning and late afternoon and evening hours for a winter day. During the night the base load values indicate the classic refrigerator repeated start to work.

During one week the load profile consists of a repeating daily profile with slight deviations during weekdays and weekend days. An exception of the typical behavior is depicted in Fig. 3b. In this example the daily energy consumption can be observed for the first half of the measurement interval. During the second half only the base load occurs. The reason for this is the absence of the family during the second half due to holidays. It is obviously that the energy consumption depends on the personal habits of the consumers. For a design of PV systems general data for the energy consumption should be used.

\subsection{Summer period}

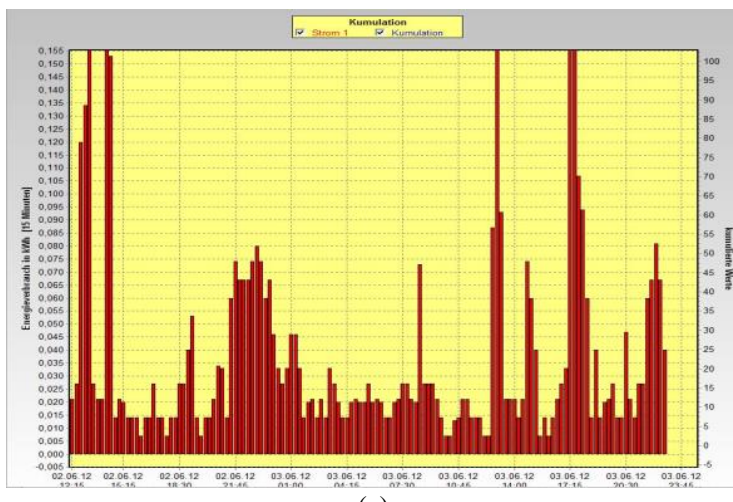

(a)

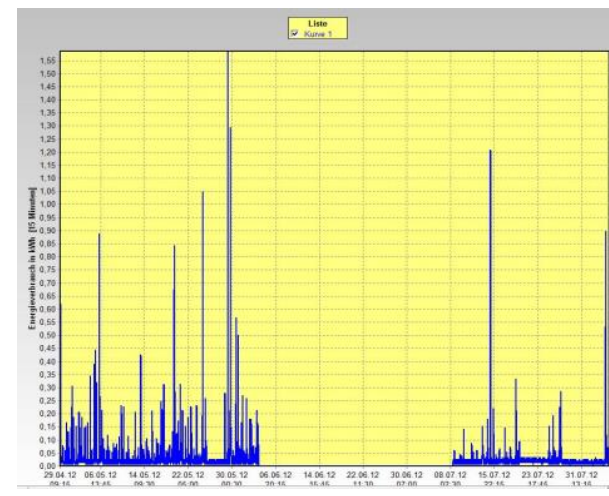

(b)

Fig. 4. Measured in summer: (a) daily load curve (b) Week measuring. 
Fig. 4a depicts the energy consumption during one summer day. The load profile shows again typical peaks during the day. Finally Fig. $4 \mathrm{~b}$ displays the energy consumption during one week. Also in this example a non-constant consumer behavior can be observed due to the absence of the consumers during one part of the week.

\subsection{Summer period}

The daily load curve in summer indicates that the highest energy demand occurs during the morning and the late afternoon and evening hours. Therefor the PV modules can be mounted with an east-west orientation in order to maximize the self-produced energy with respect to the solar irradiation during that time of the day. For the rest of the day the PV modules are capable to generate sufficient energy for the own power consumption and charge of a battery which provides energy in the evening. Thus both can be maximized self-consumption and autarky rate.

On the other hand the winter measuring shows a higher energy requirement. During this season the solar irradiation is lower. Therefor modules should be mounted with a south orientation and a smaller installation angle.

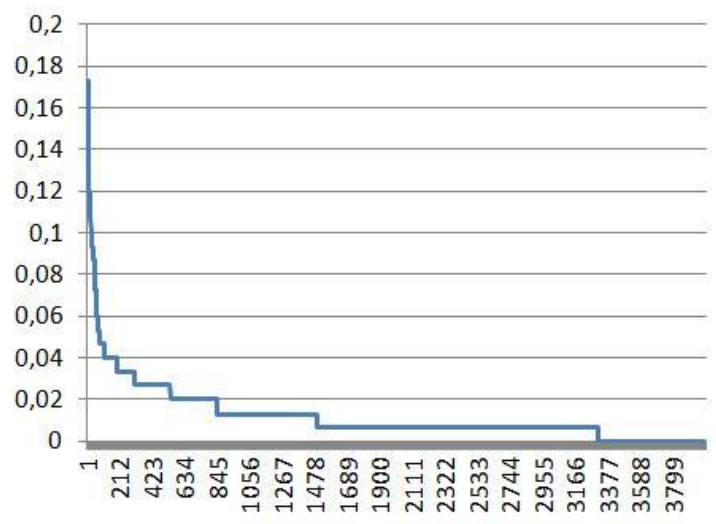

Fig. 5. Half-year measuring re-sorted.

If the energy demands are re-sorted the requirements can listed as shown in Fig. 5. In that regard the requirements are listed for one half-year. Large electric consumers like washing machines are supposed to run 1-2 times a week for 2-4 hour. The rest in one half-year consist only on base load, i.e. power for small consumers of electricity. In addition surplus energy will be used to charge a battery. The storage time depends on the charge- and discharge time of the used battery type, i.e. lithium-ion or saltwater batteries.

\section{Solar Irradiation and Plant Design}

In a first step the map of the German meteorological service DWD with the values of the global irradiation is taken into consideration. In the second step the Solar-Kataster which has been developed at the Frankfurt University of Applied Science is used. In the third step the elevation of the actual solar irradiation conditions including shadowing effects of the chosen installation site is investigated.

\subsection{German meteorological service}

The German meteorological service [4] offers an open access for all cities. In particular the maps to the global irradiation of Germany Fig, 6a allow a first assessment of the area of interest. The monthly data provides more information of the global irradiation of larger cities in Germany.

For example the total global irradiation for Frankfurt is $167 \mathrm{kWh} / \mathrm{m}^{2}$ in July 2016 and $155 \mathrm{kWh} / \mathrm{m}^{2}$ in August 2016. The chosen location of the proposed project is approximately $5 \mathrm{~km}$ north of Frankfurt so that these data can be used for the design. 


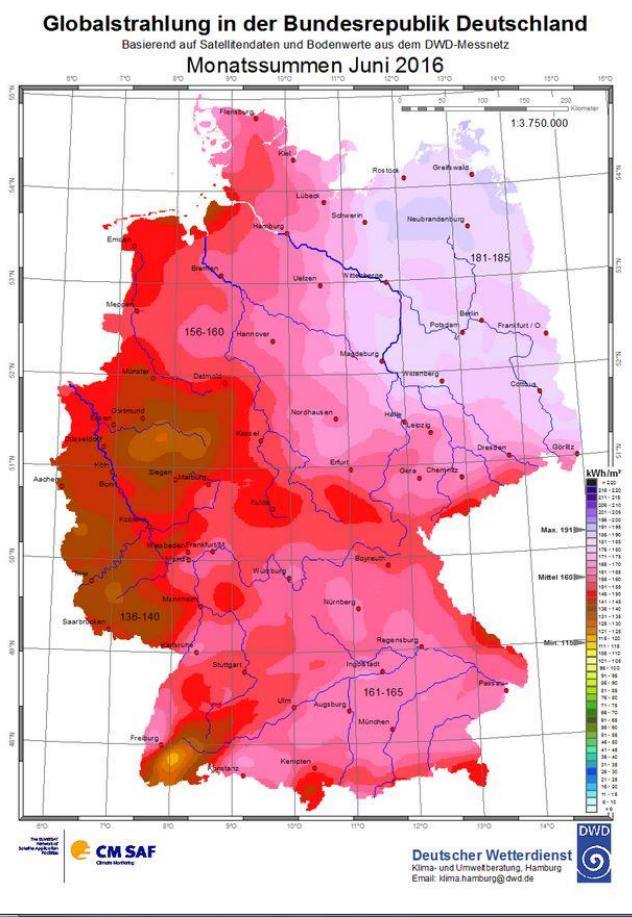

(a)

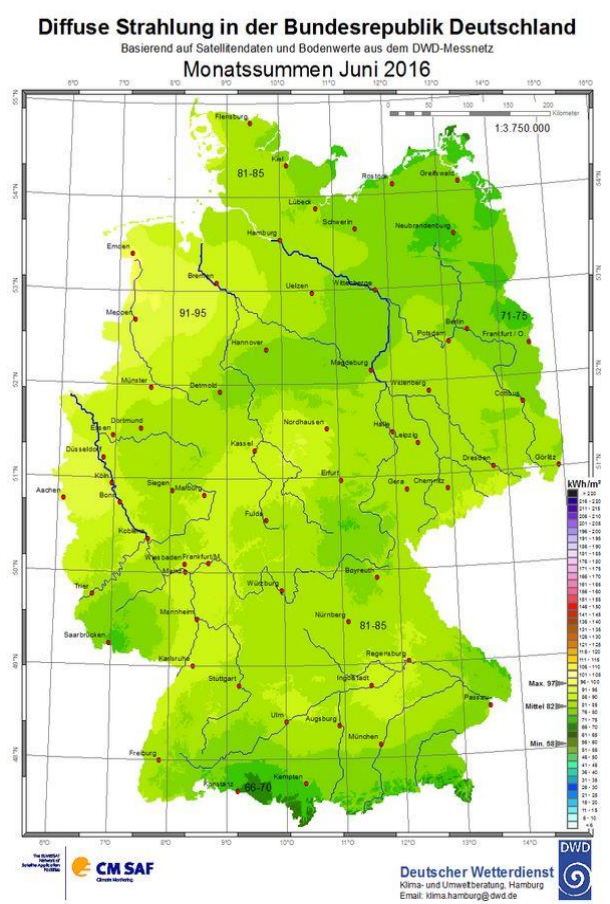

(b)

Fig. 6. German meteorological service: (a) Global irradiation (b) Diffuse irradiation.

Fig. $6 \mathrm{~b}$ shows the corresponding values of the diffuse irradiation. An assessment of the efficiency of bifacial solar modules can be carried out. Since this kind of module is active on both sides it is capable to convert light from all directions into electrical energy as indicated in Fig. 7 [5].

An increase of about $25 \%$ more yield per installed $\mathrm{kWp}$ seems to be possible in comparison to conventional modules Hence bifacial modules are selected for the proposed project.

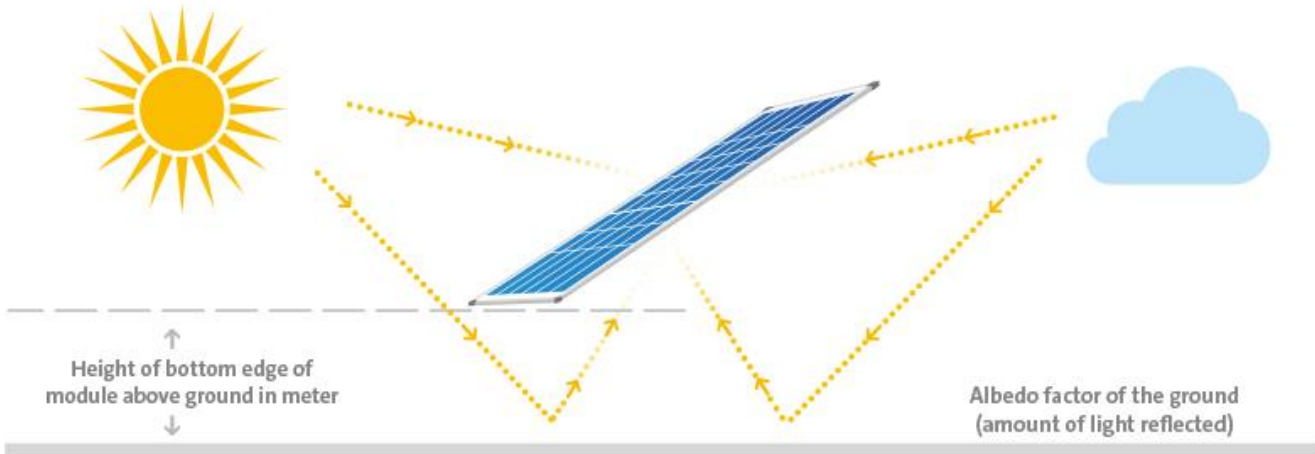

Fig. 7. Bifacial solar modules [5].

\subsection{Solar. Kartaster Hessen}

Hesse as a pilot phase becomes lifted up the data of the solar cadastral land register for the country of 30 towns. The Frankfurt University of Applied Science connects high-resolution 3D photos with the cadastral land of the property registers [6]. The online platform is developed in terms of the SUN-AREA method. 


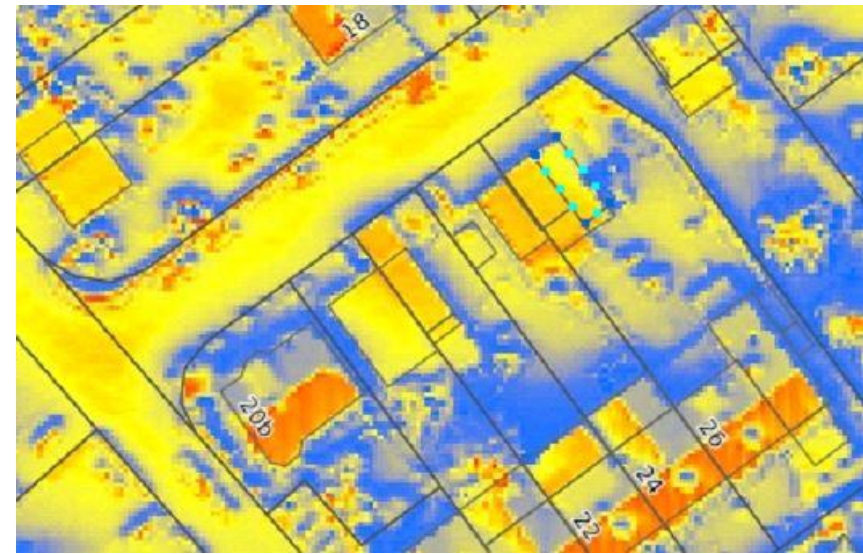

Fig. 8. Solar Kartaster Hessen.

The evaluation for the chosen location is represented in Fig. 8. It shows a flat roof of the garage. Since the PV modules can be aligned with $30^{\circ}$ in south or $10^{\circ}$ east-west as shown in Fig. 9 the roof is well suitable for a PV plant installation. Red colored areas represented all roofs up to south with $30^{\circ}$. A correction of the data could be carried out in the pilot phase here.

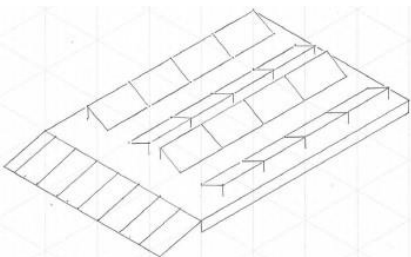

(a)

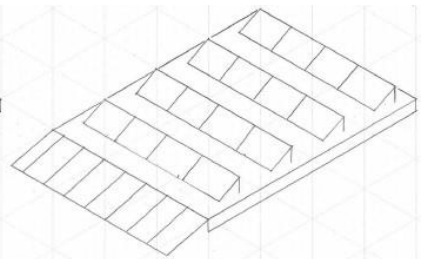

(b)

Fig. 9. PV module orientation: (a) east-west (b) south.

\subsection{Solar Kartaster Hessen}

For the design of the PV system a suitable place must be identified. The gable roof with a good south orientation seems to be suitable. The flat roof seems to be suitable for an east-west orientation, see Fig. 10. Cleaning of the modules can be realized very easy. The area should be free of shadows as far as possible during the day to attain a maximum gain of the current harvest. This, however, cannot always be reached.
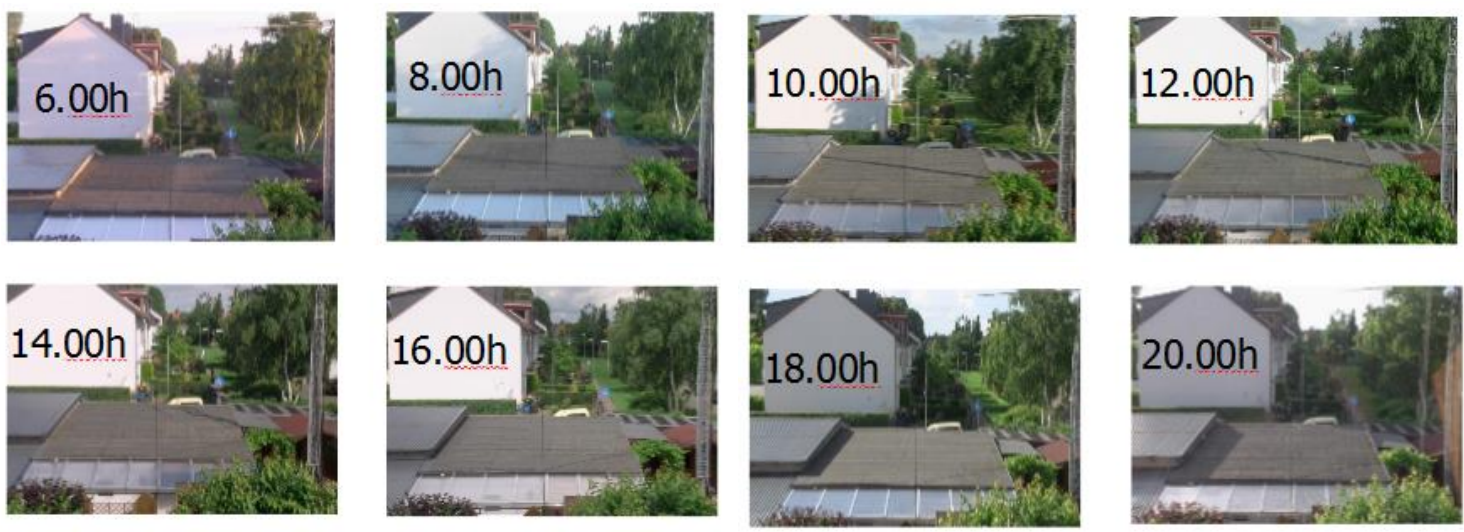

Fig. 10. Solar irradiation summer 2016.

Fig. 10 shows a picture number of the solar irradiation of a cloudless summer day in 2016. The shadowing of a mast is interesting in the morning hours, partially it moves across the possible location of 
the PV modules.

\section{Energy Storage Systems}

Electrochemical storage systems can be divided into two categories [7]:

1. External storage: electrolyzer/ fuel cell and the redox flows batteries

2. Internal storage: high temperature batteries like $\mathrm{NaS}$ or $\mathrm{NaNiCl}$ and low temperature batteries like lead, NiCd/NiMH, saltwater battery and lithium-ion batteries, see Fig. 11.

For PV applications in small power ranges low temperature batteries in particular lithium-ion batteries are best suitable for the private households

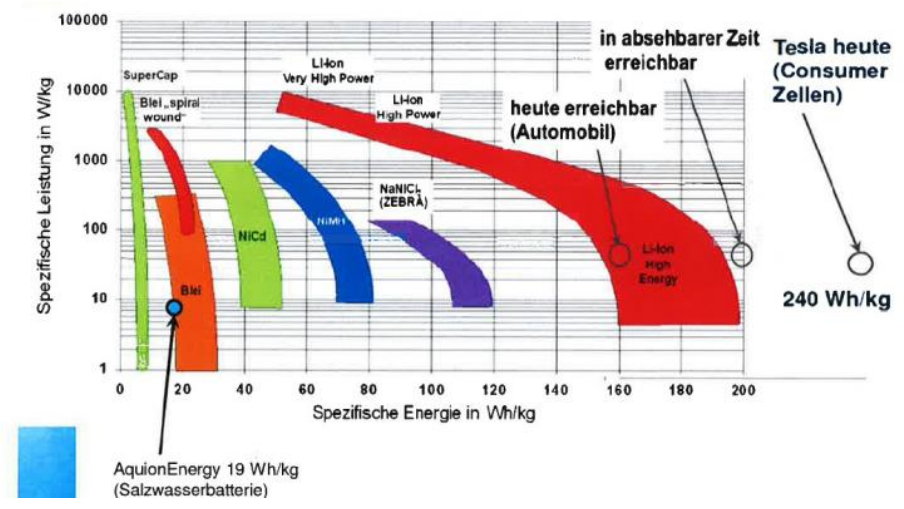

Fig. 11. Ragone diagram.

In a comprehensive approach the costs for storage systems are not insubstantial. The costs of lithiumion batteries were about $1600 €$ per $1 \mathrm{kWh} 5$ years ago. Today the costs are in the range of $800 €$ to $1000 €$ per $1 \mathrm{kWh}$. The goal is to reduce the costs to $400 €$ per $1 \mathrm{kWh}$ in order to achieve a competitive business case [8].

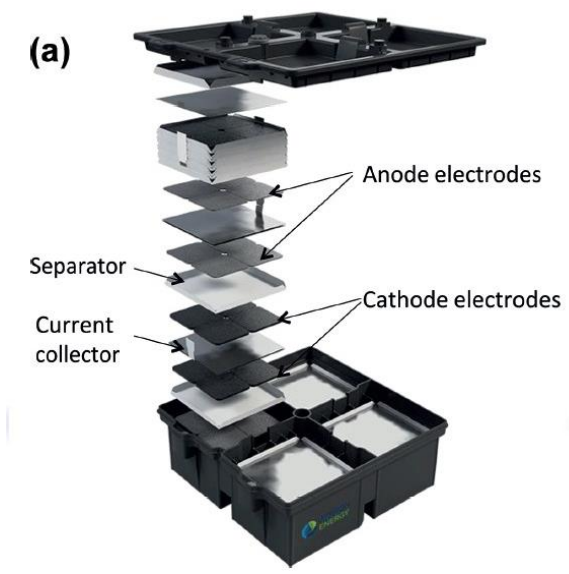

Fig. 12. Saltwater battery [8].

The saltwater battery seems to be a promising alternative to lithium-ion batteries since it is characterize by a high depth of discharge and round trip efficiency. Furthermore it is non-flammable and non- explosive. Fig. 12 shows the component arrangement [9]. Even though this kind of battery is larger and heavier than a lithium-ion one the costs are about $450 €$ per $1 \mathrm{kWh}$. In building facilities the drawback of size and weight is minor. Due to these properties the saltwater battery is chosen for the presented project [10]. 


\section{Conclusion}

The presented plant shall be built up practically after the interpretation and analysis of the energy balance and the solar irradiation. During the plant operation measurements will verify the right installation of the solar modules and the storage system [11]. An optimization of the plant can be carried out from these results in order to accomplish an increase of the autarky and self-consumption rate.

\section{References}

[1] VDE - Studie: Batteriespeicher in der Nieder-und Mittelspanungsebene , Frankfurt am Main: VDE (ETG), Mai, $2015: 96$.

[2] Weniger J. Dezentrale Solarstromspeicher für die Energiewende, Berlin: htw Berliner Wissenschafts-Verlag, 2015.

[3] Deutscher W. Klima und Umweltberatung Hamburg, 2016.

[4] Diekmann S. Scalable Multi-Level Energy Management for Residential Buildings, Bonn: International ETG Congress, November 2015.

[5] Solar World, Real Value

[6] Frankfurt University of Applied Science, Martina Klärle. [Online]. Available: http:// www.solarkataster.hessen.de

[7] Kurzweil P. Elektrochemische Speicher, Wiesbaden Springer 2015.

[8] Haselhuhn R. Energiespeicher -Planung und Installation am Niederspannungsnetz, Offenbach am Main: VDE Verlag GmbH, 2016.

[9] Aquion Energy, Aqueous Hybrid Ion (AHI) Chemistry.

[10] Becker A. Elekctricity Storage System in Medium- and Low-Voltage Networks, Bonn: International ETG Congress November 2015

[11] Hölker D. Evaluation of Self-Sufficiency by Variation of Future Energy Prosumers in Households, Bonn: International ETG Congress, November 2015 